Gut, 1972, 13, 556-558

\title{
The site of denervation in achalasia
}

\author{
SIDNEY COHEN, ROBERT FISHER, AND ARTHUR TUCH
}

From the Gastrointestinal Section, Department of Medicine, University of Pennsylvania at the Hospital of the University of Pennsylvania and Veterans Administration Hospital, Philadelphia, Pennsylvania

SUMMARY Lower oesophageal sphincter supersensitivity to gastrin I and cholinergic stimulation has recently been described in patients with achalasia. To determine the pathogenesis of this finding, the lower oesophageal sphincter was tested to a cholinesterase inhibitor, edrophonium chloride. Edrophonium chloride significantly increased the lower oesophageal sphincter pressure both in normal subjects and in patients with achalasia. The preservation of this response in the presence of denervation supersensitivity suggested intact postganglionic cholinergic nerves and, thus, a preganglionic site of denervation in achalasia.

It has recently been shown that the lower oesophageal sphincter in patients with achalasia is supersensitive to both gastrin I (Cohen, Lipshutz, and Hughes, 1971) and direct cholinergic stimulation (Cohen and Guelrud, 1971). Although this finding is attributed to denervation, the site of this lesion is not generally agreed upon. It has been suggested that the primary neurological lesion in achalasia is central (Cassella, Brown, Sayre, and Ellis, 1964). An abnormality has been described in the dorsal vagal nucleus in the brain stem. This finding is contrary to the generally accepted concept that achalasia is due to destruction of cholinergic ganglia in the wall of the oesophagus (Trounce, Deuchar, Kauntze, and Thomas, 1957; Misiewicz, Waller, Anthony, and Gummer, 1969). Since anatomical studies have not resolved this controversy, it seemed reasonable to investigate this problem further with pharmacological agents.

To determine the site of denervation, the response of the lower oesophageal sphincter to a cholinesterase inhibitor was studied. Only a structure that can synthesize and release acetylcholine would respond to the cholinesterase inhibitor (Daniel, 1968; Goodman and Gilman, 1966). A structure that has been denervated at the ganglionic level would not release acetylcholine and would, therefore, not respond to a compound that only enhances the effect of locally released neurotransmitter. In preganglionic denervation, acetylcholine would still be released from intact

Please address requests for reprints to: Dr Sidney Cohen, Hospital of the University of Pennsylvania, 34th and Spruce Streets, Philadelphia, Pennsylvania, 19104.

Received for publication 15 May 1972. postganglionic nerves and the cholinesterase inhibitor would elicit a response (Anderson, 1905; Hukuhara, Nakayama, and Fukuda. 1965). Therefore, by simply determining the response to a cholinesterase inhibitor, one could further localize the site of denervation of the lower oesophageal sphincter in achalasia.

\section{Methods}

Studies were performed in two groups of patients, 10 'normals' and 10 patients with achalasia. Patients with normal upper gastrointestinal radiographic evaluation aged 22 to 76 years (mean, 44) were selected as controls before manometric evaluation. The patients with achalasia, aged 18 to 66 years (mean, 46), met the following criteria: (1) radiographic and cineradiographic diagnosis of achalasia (criteria consist of absence of peristalsis with impaired oesophageal emptying in the upright position, oesophageal dilatation with smooth, tapered narrowing at the cardiooesophageal junction, and the absence of a mass lesion); (2) manometric recording showing total absence of distally progressive oesophageal peristalsis; (3) endoscopic evaluation with free passage of the oesophagoscope into the stomach to rule out organic obstruction; (4) an increase in oesophageal pressure of $20 \mathrm{~mm} \mathrm{Hg}$ above the resting value recorded by open-tipped catheters upon the administration of acetyl-B-methacholine (mecholyl chloride) 2 to 10 mg subcutaneously; and (5) no history of prior therapeutic procedures for achalasia.

Water-filled polyvinyl catheters, $1.4 \mathrm{~mm}$ internal diameter, were used to transmit intraluminal pressures to external transducers (Statham P23BB). 
The output from each transducer was recorded on a Beckman curvilinear ink-writing recorder. Three recording catheters were arranged to form a single assembly with three side orifices, $1.4 \mathrm{~mm}$ diameter, at $5-\mathrm{cm}$ intervals. The pressure recording tubes were infused with distilled water, by a syringe pump, at a constant rate of $1.2 \mathrm{ml}$ per minute. All pressures are expressed using gastric pressure as a zero reference. The manometric records were tabulated using the midrespiratory pressure from the segment of the lower oesophageal sphincter manifesting the maximal pressure.

Manometric studies were performed with the patient resting quietly in the supine position, after an eight-hour fast. Belt pneumographs around the chest and over the larynx were used to monitor respiration and swallowing, respectively. The recording assembly was positioned with all orifices in the stomach. Following a 20-min rest period, the assembly was moved at $1-\mathrm{cm}$ intervals through the full length of the oesophagus. Following this diagnostic evaluation, the recording assembly was positioned and anchored so that pressures were simultaneously recorded from the oesophagus, lower oesophageal sphincter, and stomach.

Edrophonium chloride (Tensilon) was given intravenously as a single injection over a 30-second period. The dose that gave a maximal increase in sphincter pressure, $80 \mu \mathrm{g} / \mathrm{kg}$, was administered to all patients. The peak level of sphincter pressure attained was tabulated. The rise in pressure was also expressed as a percentage increase above the preinjection level.

\section{Results}

The resting lower oesophageal sphincter pressure in 10 normal subjects was $18.6 \pm 1.2 \mathrm{~mm} \mathrm{Hg}$ (mean \pm $\mathrm{SE}$ ), while that in the 10 patients with achalasia was $46.8 \pm 4.2 \mathrm{~mm} \mathrm{Hg}$. In each patient, edrophonium chloride gave a rise in lower oesophageal pressure. The response occurred and was terminated within 10 minutes of the injection. The peak absolute and percentage responses are shown in Table I. Although the peak response in the patients with achalasia exceeded the peak response in the normals, the

\begin{tabular}{llll}
\hline & $\begin{array}{l}\text { Resting } \\
\text { Pressure }(m m ~ H g)\end{array}$ & $\begin{array}{l}\text { Change in } \\
\text { Pressure }(m m ~ H g)\end{array}$ & $\begin{array}{l}\text { Percentage } \\
\text { Response }\end{array}$ \\
\hline Normal & $18.6 \pm 1.2$ & $31.8 \pm 4.2$ & $170.8 \pm 22.5$ \\
Achalasia & $46.8 \pm 4.2$ & $85.0 \pm 5.1$ & $181.8 \pm 11.0$ \\
\hline
\end{tabular}

Table I The lower oesophageal sphincter response to edrophonium chloride $(80 \mu \mathrm{g} / \mathrm{kg})$

Each result represents the mean \pm one standard error of the mean in 10 patients. percentage response showed no statistical difference $(P>0.05)$.

\section{Discussion}

The purpose of this study was to determine whether the lower oesophageal sphincter in patients with achalasia could respond to a cholinesterase inhibitor, a compound that would only act in the presence of acetylcholine (Daniel, 1968; Goodman and Gilman, 1966). The preservation of the response to the cholinesterase inhibitor in patients with achalasia suggests that sphincteric denervation is preganglionic in this disease.

The validity of using a cholinesterase inhibitor to test the presence of local acetylcholine release has been established in basic pharmacological observations. After ganglionic destruction, cholinergic nerves to smooth muscle degenerate and acetylcholine is no longer locally liberated. Under such circumstances a cholinesterase inhibitor fails to manifest its effects. This was initially demonstrated by Anderson in 1905 when he demonstrated failure of pupillary constriction to physostigmine following removal of the ciliary ganglion (Anderson, 1905). More recently, Hukuhara has shown that ganglia-free smooth muscle preparations do not respond to cholinesterase inhibition (Hukuhara et al, 1965). The absent cholinergic response to cholinesterase inhibitors has been generally accepted as a reliable index of postganglionic denervation (Daniel, 1968).

The neurogenic basis of achalasia has been established by histopathological observations (Trounce et al, 1957). There has been no attempt to evaluate specifically the site of denervation pharmacologically and resolve the conflicting results obtained by ganglion cell counts in the oesophagus. Most recently, supersensitivity of a hypertensive lower oesophageal sphincter in achalasia has been demonstrated independently for both gastrin and direct cholinergic stimulation. The analogy of these findings to the supersensitivity to indirect and direct acting adrenergic agents in the experimentally denervated cat nictitating membrane seemed obvious. Trendelenburg had shown that adrenergic denervation was of two distinct types, preganglionic and postganglionic (Trendelenburg, 1966). Preganglionic denervation or decentralization gave a supersensitivity that was moderate but of equal magnitude for adrenergenic agents that acted directly on the muscle membrane or indirectly through epinephrine release. Postganglionic denervation was characterized by a marked supersensitivity only to agents that acted directly. The response to indirect acting agents was markedly diminisned or absent. Since gastrin acted indirectly through acetylcholine release at the lower 
oesophageal sphincter (Lipshutz, Tuch, and Cohen, 1971), the analogy to the experimental model was apparent. The moderate, approximately equal supersensitivity to gastrin and cholinergic drugs suggested a preganglionic denervation of the lower oesophageal sphincter in achalasia. The preservation of the response to the cholinesterase inhibitor further strengthened a preganglionic site of denervation. It is of interest that muscle strips taken from the lower oesophageal sphincter in patients with achalasia have also been shown to respond to cholinesterase inhibitors (Misiewicz et al, 1969).

Although the data in this study were used to support the hypothesis that denervation of the lower oesophageal sphincter in achalasia was preganglionic, several other possibilities should be considered. First, the denervation may be only partial allowing some acetylcholine release to remain present. Second, the preserved response to a cholinesterase inhibitor may be the manifestation of locally released acetylcholine from non-neural stores in the muscle itself (Burn, 1954). The concept of partial ganglionic denervation is difficult to exclude. The response to a cholinesterase inhibitor is generally utilized in a qualitative fashion. Themagnitude of response therefore has no precedent in resolving this issue. Also, since we utilized the lowest dose of edrophonium that gave a maximal response, we cannot compare shifts in dose response curves to assess these changes. Our data simply indicate that the maximum percentage response to a cholinesterase inhibitor is similar in normals and in patients with achalasia, suggesting preservation of acetylcholine release. The concept of local acetylcholine in muscle has been described in animals but has received no attention in man. Although our findings could be explained by this mechanism, the possibility seems less likely since the presence of nonneuronal acetylcholine has not been demonstrated in human gastrointestinal smooth muscle.

In summary, the lower oesophageal sphincter in patients with achalasia increased its pressure in response to a cholinesterase inhibitor. This observa- tion suggested that acetylcholine was being released at the muscle membrane of the lower oesophageal sphincter. The previously demonstrated supersensitivity to gastrin and direct cholinergic stimulation therefore may be due to a preganglionic site of denervation.

This work was supported by Veterans Administration clinical investigator and training grant (TR15) funds as well as USPHS training grant T01-AM-5462-06. The authors wish to thank Dr George Koelle for his advice in performing these studies.

\section{References}

Anderson, H. K. (1905). The paralysis of involuntary muscle. III. On the action of pilocarpine physostigmine and atropine upon the paralysed iris. J. Physiol. (Lond.), 33, 414-438.

Burn, J. H. (1954). Acetylcholine as a local hormone for ciliary movement and the heart. Pharmacol. Rev., 6, 107-112.

Cassella, R., Brown, A., Sayre, G., and Ellis, F. (1964). Achalasia of the esophagus: pathologic and etiologic considerations. Ann. Surg., 160, 474-487.

Cohen, B. R., and Guelrud, M. (1971). Cardiospasm in achalasia: Demonstration of supersensitivity of the lower esophageal sphincter. Gastroenterology, 60, 769.

Cohen, S., Lipshutz, W., and Hughes, W. (1971). Role of gastrin supersensitivity in the pathogenesis of lower esophageal sphincter hypertension in achalasia. J. clin. Invest., 50, 1241-1247.

Daniel, E. E. (1968). Pharmacology of the gastrointestinal tract. In Handbook of Physiology, Sect. 6, Alimentary Canal, edited by C. F. Code, Vol. 4, 2267-2324. American Physiological Society, Washington, D.C.

Goodman, L., and Gilman, A. (1966). Anticholinesterase agents. Pharmacological Basis of Therapeutics, 3rd ed., pp. 441-463. MacMillan, New York.

Hukuhara, T., Nakayama, S., and Fukuda, H. (1965). On the problem whether the intestinal motility is of a neurogenic or myogenic nature. Jap. J. Physiol., 15, 515-522.

Lipshutz, W. Tuch, A., and Cohen, S. (1971). A comparison of the site of action of gastrin I on lower esophageal sphincter and antral circular smooth muscle. Gastroenterology, 61, 454-460.

Misiewicz, J. J., Waller, S. L., Anthony, P. A., and Gummer, J. W. P. (1969). Achalasia of the cardia: pharmacology and histopathology of isolated cardiac sphincteric muscle from patients with and without achalasia. Quart. J. Med., 38, 17-30.

Trendelenburg, U. (1966). Mechanisms of supersensitivity and subsensitivity to sympathomimetic amines. Pharmacol. Rev., 18, 629-640.

Trounce, J. R., Deuchar, D. C., Kauntze, R., and Thomas, G. A. (1957). Studies in achalasia of the cardia. Quart. J. Med., 26, 433-443. 